\title{
Viewpoint Makes Meaninglessness Meaningful
}

\author{
Yunfeng Shi, Yuhong Xie \\ College of International Studies, Southwest University, Chongqing, China \\ Email: shiyf@swu.edu.cn,xieyh@swu.edu.cn
}

How to cite this paper: Shi, Y. F., \& Xie, Y. H. (2016). Viewpoint Makes Meaninglessness Meaningful. Open Journal of Modern Linguistics, 6, 429-440.

http://dx.doi.org/10.4236/ojml.2016.66038

Received: October 23, 2016

Accepted: November 14, 2016

Published: November 17, 2016

Copyright $\odot 2016$ by authors and Scientific Research Publishing Inc. This work is licensed under the Creative Commons Attribution International License (CC BY 4.0).

http://creativecommons.org/licenses/by/4.0/

\begin{abstract}
What makes some seemingly meaningless sentences frequently useful in the daily communication and thus meaningful? This paper proposes an innovative perspective of studying pragmatic meaning via considering the language users' viewpoint, which influences and determines the extent of subjectivity in choosing appropriate meaning among multiple layers of meaning. It is argued that viewpoint makes vague or even meaningless language meaningful in that meaning is, first of all, multilayered; then it is optional and subjective, and finally it is chosen from all the possible options of meaning or meaning potential with regard to the language user's various kinds of viewpoints.
\end{abstract}

\section{Keywords}

Viewpoint, Meaning, Multilayeredness, Optionality, Subjectivity

\section{Introduction}

Meaning has been studied for long and still attracts the interests of many linguists. Meaning has been categorized for many times and many linguists still intend to categorize it anew. Semanticists believe that it is literal, explicit, and context-independent. Pragmaticians believe that it is implied, implicit, and context-dependent. Moreover, meaning is also relevant to the language user's viewpoint, which exerts great impact on their creation and interpretation of meaning.

(1) My father is a man.

(2) War is war.

(3) Boys are boys.

(4) A: What do you mean?

B1: Oh, come on. I'm just joking!

B2: I mean it's not a good idea.

B3: I mean what I say. 
The first reaction when one reads or hears sentences (1)-(3) would most likely be that they are meaningless or even nonsense because common sense tells us that nobody's father is not a man, war is not peace, and boys will never be girls. Or, when we are asked (4) angrily, or doubtfully, or uncertainly, our answers may vary considerably according to our diverse viewpoints. For example, we may answer (4) B1 to soften the tense atmosphere, or (4) B2 to show the candidness, or even (4) B3 to show the questioner that we mean literally and will keep our promise and act out accordingly.

But what if they are really uttered and heard from time to time? What makes this kind of sentences frequently useful in daily communication and thus meaningful? The author proposes an innovative perspective of studying pragmatic meaning via considering the language users' viewpoint, which influences and determines the extent of subjectivity in choosing appropriate meaning among multiple layers of meaning. In this essay, it is argued that it is viewpoint that makes vague or even meaningless language meaningful in that meaning is, first of all, multilayered; then it is optional and subjective, and finally it is supposed to be chosen from all the possible options of meaning or meaning potential with regard to the language user's various kinds of viewpoints.

\section{Multilayeredness of Meaning}

What is the meaning of "meaning"? Lyons (1977: pp. 1-5) summarizes from ten explanatory sentences that "meaning" can be explained or understood in relation to two notions: intention and significance (or value). It is common sense that a word or an expression rarely has only one meaning. On the contrary, it has more than one facet, aspect, or dimension of meaning. There are distinctions between literal meaning and figurative meaning, descriptive meaning and expressive meaning, epistemic meaning and sociocultural meaning. Löbner (2002: p. 11) lists three levels of meaning: expression meaning, utterance meaning, and communicative meaning. Expression meaning is context-independent. Utterance meaning is context-dependent. Communicative meaning is the meaning of an utterance as a communicative act in a given social setting.

Regardless of the above listed categories of meaning, the linguistic study of meaning generally falls into semantics and pragmatics. The former focuses on the literal meaning, or the core of the whole meanings. Just as many semanticists believe, an utterance or a sentence does not necessarily have implied meaning all the time. In many cases, they do mean literally. The structure, the wording, and the form are unmarked, and they realize the function and represent meaning in a congruent way. The latter deals with the implied meaning, which is termed "implicature" by pragmaticians. Implicature is refined, extended and enriched from the literal meaning in a certain context. Therefore, it can be gained or located only by the presence and assistance of such factors as context, communicative function, and viewpoint of language users.

Meanings are multilayered in that a word usually has many meanings, which we call polysemy. That is to say, a word is usually polysemous, or multi-meant. For example, "hand" basically refers to either of the top parts of human's upper limbs. This is the denotative meaning, or conceptual meaning, or literal meaning represented in dictio- 
nary definitions. Besides, this word can also refer to the personnel who use hands to work. This is one of its connotative meanings, or metaphorical meanings, which are the semantic association that a word has. Besides, this word can also be used as a verb, meaning "give" or "pass". Sometimes some words and expressions may have social meaning, which tells about the speaker's social position or social background. For example, the use of "green hand" shows the speaker's feeling or attitude towards the person he called "green hand". The speaker is most probably an experienced and skillful expert of higher social status or at least not a "green hand" himself.

More often than not, social and cultural meaning may result from the speaker's ideology and viewpoint. It is doubtful that parents losing a son in war and weapon manufacturers making a fortune in war may share anything in common when the former saying (1) because they have enormously diverse ideology of war and then form a corresponding viewpoint of war. For another example, the westerners would be confused and astonished to hear Chinese people call themselves "descendants of dragon (Long)" because the former's ideological and cultural image of dragon differs greatly from the latter's.

Communicative meaning comes from authentic situation of communication. It is said that in the latter half of last century when some westerners firstly travelled in China, rural areas in particular, they might wonder whether Chinese people would treat them a dinner or cared about their privacy because they often asked such questions like (6). Now, globalized international communication has overcome this kind of communicative hindrance. It becomes a common sense that in different cultures, greetings can be realized either in an English way (5) or a Chinese way (6), depending upon the speakers' location in the UK or China.

(5) How are you?

(6) Have you had your dinner?

\section{Optionality of Meaning}

Meanings, being formal (lexical, clausal, sentential), or being functional (social, cultural, ideological, interpersonal, communicative), are optional, or alternative in that they are available to be chosen or another possibility is accessible. Lexical meanings have an effectively invariant core: when a word is used, that word will dependably evoke a definable core in the minds of people who hear the word being used. A speaker will be responsible for having intended to convey this core meaning, or he has wanted to evoke this understanding in the other. And a listener will be accountable for having understood the word with that meaning as long as they have understood the utterance in which the word was used. Enfield (2015: p. 100) argues that meaning has a layered and composite nature because firstly, meaning is anthropocentric in that it is grounded in the viewpoints and concerns of our species; secondly, word meaning varies dramatically across languages so that the corresponding relevant culture provides a source of viewpoints and concerns that are both essentially human and yet potentially specific to a single human group or speech community. 
Culture is a bit like a vocabulary in that there is a vast range of meanings that are available to people, so vast that most are not generally used. They use culture much more actively to develop an understanding of their life in the world, to experience, create and maintain their webs of meaning. People then use culture to develop a personal identity and sense of self. In other words, they adapt and blend different cultural elements to create a unique way of making and choosing meaning.

Thoughts, images, or intentions lie inside or behind each instance of actual words, and these are often amenable to either a more or less detailed verbal phrasing than the one chosen at any one time (Riemer, 2005: p. 29). In using language it is a common experience that one's purpose could have been equally well fulfilled if a different synonymous form of words had been used instead of the one actually chosen. One of the earliest senses of the verb "mean" in English is "intend", or "have in mind as a purpose or intention". An identification of meaning with mental experience is facilitated by the fact that as hearers, too, it is common experience that language activates ideas. A hearer will also probably attribute similar internal experiences to the speaker as part of the explanation of why the words in question, rather than others, were chosen. Probably, in choosing the words he chose, the speaker intended the hearer to have similar internal experiences or ideas to those he had.

Systemic Functional Linguistics (SFL) provides a theory of language that concerns with the description of how language makes meaning in context (Halliday, 1994). This theory provides multidimensional semiotic space within which the analyst can explore and describe the creation of meaning through a systematic analysis of the choices made in a text and their consequent selections in the lexicogrammatical systems. SFL interprets language as meaning potential where all strata of the linguistic system contribute to the making or realizing of meaning. This contribution is functionally a matter of choice. The phonological system realizes meaning by choosing the sound of wordings; the lexicogrammatical system realizes the meaning by choosing resources of wordings like lexis and grammar; the semantic system realizes meaning by choosing contextual resources that enact and interpret meaning as linguistic and contextual one. SFL considers that language performs a number of different functions and that any piece of language is likely to be the result of choices made on different functional levels.

The theory behind Halliday's account is also known as systemic since it is a theory of meaning as choice, by which a language is interpreted as a network of interlocking options. Halliday's model is designed for the study of language as communication; meaning is attributed to the writer's or speaker's motivated linguistic choices, which systematically relate to a wider socio-cultural framework. According to Halliday (1994), choices of wording and syntactic structure are linked to the different linguistic or lexicogrammatical realizations in a text.

System is a notion central to SFL and provides the semiotic environment for structural description. Halliday (1994) regards a system network as a theory of language as choice. It represents a language as a resource for making meaning by choosing from a context and a set of possibilities. Within the system of language, especially that of a lex- 
icogrammar, any stratum is a network of interrelated options or alternative choices. Particular choices that are taken up have value relative to those not taken up. The choice of one item in a system necessarily excludes the possibility of another. Take, for example, the aspect system in English grammar, which is viewed as very general. The choice of perfective aspect means the completion of an act, thus excludes the possibility of progressive aspect. The lexis is seen as more specific or delicate. Halliday (1978: p. 43) argues that the lexicon is the most delicate grammar and as the lexicogrammatical options become more and more specific, they tend more and more to be realized by the choice of a lexical item rather than the choice of a grammatical structure.

The three metafunctions in SFL are essentially three types of meaning. A clause or a text embodies all the three metafunctions which allow the creation of multiple meanings: (a) the ideational meaning/function is creation of clause or text as experience and represents people, objects, events, states of affairs in the world with functions such as actor/agent, process, goal, circumstances; (b) the interpersonal meaning/function is creation of clause or text as exchange and expresses interpersonal relationships and the speaker's attitude to these representations with functions such as subject, object, mood; (c) the textual meaning/function is creation of clause or text as message in context and expresses both the ideational and interpersonal function in a cohesive and appropriate manner (Halliday, 1994; Halliday \& Matthiessen, 2004). From a systemic functional perspective, each text is expressed through clauses and the analyst's task is to uncover the (potentially ideological) meaning of the text through the patterns of their functional representations (Eggins, 2004). Grammar is at once both a grammar of the system and a grammar of the text: a resource for making meaning (Halliday \& Mathiessen, 2004: p. $31)$.

Metafunctional diversification is a key aspect of the organization of the content level of language (Caffarel, 2010). Choices of the three metafunctions correlate to the three corresponding discoursal components of context: field of discourse, tenor of discourse, and mode of discourse. Caffarel (2006: pp. 209-211) analyzes the correlation between these contextual variables and linguistic choices within the three metafunctions in the context of a linguistic lecture: the "institutional setting" influences choices in transitivity and lexis, the "relationship between participants" influences the dynamics of the exchange in the classroom and the choices in mood, and the "channel of communication adopted" influences textual choices and the organization of the flow of information.

The creation of meaning in SFL involves three notions of logogenesis, phylogenesis, and ontogenesis. They can also provide means to meaning potential and choice of meaning. Logogenesis means the synchronic creation of meaning in a text through instantiation by means of choosing particular features from the overall system. Phylogenesis is the creation of meaning from a diachronic systemic perspective, looking at the evolution of the system from a historical perspective. Ontogenesis concerns with the evolution of the linguistic system in the individual from protolanguage to language. The most important process of this evolution from protolanguage to adult language is the shift from a bistratal linguistic system (content, expression) to a tristratal linguistic 
system (semantics, lexicogrammar, phonology), in which content is further stratified into semantics and grammar. The ontogenetic development of grammar increases our meaning potential by allowing for metafunctional diversification or for multiple meanings simultaneously as a single structural frame. And the tristratal linguistic system gives the means to express incongruently and metaphorically.

According to Caffarel (2010), Stratification and instantiation in SFL also provide different perspective to explore language. The former refers to the organization of language system in context into strata like context, semantics, lexco-grammar, phonology/graphology. The relationship between the strata is one of realization. The latter is a cline that provides two perspectives from which to look at language, from the potential or from the text. Halliday (1994) explains that system is language seen from a distance as meaning potential, and text is language from nearness as instances derived from the potential. In other words, there is only one phenomenon about language. Saussure's distinction of langue and parole results from different observational positions, i.e. viewpoints.

As in all language operations, choices are meaningful when contrasted with the full paradigm of options that could have been, but were not, instantiated in the text. Though, at a time, one function can be more prominent, most constituents of sentences embody more than one function through their ability to combine two or more syntactic roles. Consequently, all linguistic choices are meaningful and all linguistic choices are stylistic. To conclude, the choice of wording and function all depends on the language user's perspective, or viewpoint.

\section{Subjectivity of Meanings}

Both speaker and hearer in communication use the language subjectively. On the speaker's stance, he may suppose the linguistic form he chose will best represent his meaning. When he has an intention to communicate, he hypothesizes that there must be many linguistic forms available and some may help him achieve this goal better than others. Then he will choose the linguistic form he thinks most apt to represent his meaning and he supposes that the hearer will understand what he intends to mean. On the hearer's stance, he will list as many possible layers of meaning from the speaker as possible. Then he will choose the most relevant and hence most possible meaning. The hearer may hypothesize what the speaker may mean and choose what he thinks is right among all the possible meanings ha can get from the linguistic forms given by the speaker.

Whether meaning is useful is a matter of subjectivity. Enfield (2015: p. 1) holds that 1) word meanings reflect, and create, a deeply subjective view of the world; 2) word meanings are the historical product of their utility as means to people's communicative ends. Meaning is often thought of as representation, but at the core of language use as decision-making. The constant questions concerning meaning are: What do you mean by that? Why do you say in that way? How shall I respond? What will they think I mean? Enfield (2015: p. 2) concludes that "Meanings are above all, and necessarily, 
useful. If the meanings are not useful for people they would not exist". In other words, meanings are useful only to those who use them, and therefore subjective.

Many authors have championed the idea that the concepts conveyed by language are fundamentally subjective in character, and that language is not a means for reflecting how things are, but rather a means for portraying it in certain ways, depending on a speaker's communicative goals (Enfield, 2015: p. 2). The meaning of words and other linguistic units are deeply subjective and anthropocentric in nature. One kind of subjectivity is associated with human's propensity to focus on the psychological elements such as beliefs, intentions, desires and goals that we assume underlie the controlled behaviors of others. The inclination is so natural that we should not be surprised to see it encoded in words related to human actions. Another kind of subjectivity is entailed by the notion of affordances. We believe that perception is intrinsically subjective, and oriented to possibilities for action depending on both the properties of the thing being perceived and the properties of the entity doing the perceiving, i.e. the perceiver. Words and their meanings would not exist if they had not evolved for communicative purpose. This performative power of human purposes ensure that words for things do not just serve to pick out referents, but to portray thing in ways that are relevant to, and measured by, the subjective and culture-grounded interests of people.

(7) The cat ruined my sleep last night.

(8) Cathie woke me up many times late last night.

Löbner (2013: p. 33) argues that every utterance serves, consciously or not, expressions of our personal emotion, opinion, judge, or attitude. For example, when hearing (7) we will probably imagine a manner displaying a negative feeling of complaint, anger, and frustration. This is demonstrated by the use of the subject "the cat" instead of a name or even nickname, and the use of the verb "ruin", which is an absolutely negative behavior. Furthermore, one's personal experience proves that any interruption or breaking on the sleep is destined to be an annoying behavior. However, this sentence can also be uttered in a neutral manner or in a way that shows different emotions of tolerance, relief, or joking. For example, by saying (8) the speaker displays his personality and attitude of tolerance and concern towards the cat (nicknamed Cathie). Therefore, whatever we say will be expressions produced more or less alongside with our personal, and thus subjective, sensation, emotion, affection, opinion, evaluation, or attitude.

(9) You are stepping on my toe!

(10) A: Ouch!

B: I'm awfully sorry to have stepped on your toe.

Furthermore, these personal feelings, sensations and attitudes and evaluations can be expressed subjectively by means of expressive language such as interjections or exclamatory sentences. For example, the description (9) and the responding interjection (10) A differ in that the former is a sentence with regular descriptive meaning, while the latter expresses a vocal reaction of a sudden pain or even a kind of warning of implication involving an apology (10) B.

The correct use of expressive language is a matter of subjective behavior since all these expressions express their personal feelings and attitudes which are perceptible 
only to the speaker for the sake of their personal judgment. For example, whether or not the speaker decides to make his hearer believe that his toe is aching is determined by the fact that the speaker found that his toe is being stepped and aching and he intends to warn against the ache-causer.

In English as well as in Chinese or maybe many other languages, there are many nouns and vocatives are emotionally charged. They may have the descriptive meaning of person (the first, second, or third) on the one hand and expressive and emotive meaning of likes or dislikes, affirmation or negation on the other. For example, "idiot", "bastard", "dear", "sweetie" in English express respectively meaning of offence and affection; for other examples in Chinese, "Laozi (your father)" and "Ni yeye (your grandpa)" express not only the first person but an arrogant and rude "I" while "Biren" and "Xiaoke" express a derogated and humiliated first person "I". More interestingly, in face-to-face communication or in letters Chinese would address other people's son "Linglang (your honored son)" and their own son "Quanzi (dog's son)" to express politeness or courtesy. Therefore, whether noun or vocative add positive or negative aspect to the descriptive meaning depends fundamentally on the speaker's personal communicative intention and their subjective choice in the context of situation.

\section{Viewpoint-Oriented Nature of Meaning}

Before we illustrate how viewpoint shapes meaning, we have to define notions like viewpoint, meaningfulness, and meaninglessness and classify them. Viewpoint first of all is a physical position we view something, and the way we view this something. Then it can also be a mental or psychological position or way we perceive something. This viewpoint may conclude our ideology, belief, attitude, feeling, encyclopedic knowledge, cognitive pattern. We can call it cognitive viewpoint. The third is the realization of the previous two viewpoints in language, which can be termed as linguistic viewpoint. Linguistic viewpoint is greatly influenced by physical viewpoint and cognitive viewpoint, and therefore, can be viewed as a combination of the previous two. It involves various ways of using language like choice of lexicogrammar, wording, word sequence, structure, et al.

Meaningfulness and meaninglessness can be classified in a hypothetical way in terms of form and function: those formally meaningful and functionally meaningful; those formally meaningful yet functionally meaningless; those formally meaningless yet functionally meaningful; those formally meaningless and functionally meaningless. What we are discussing in this essay is those formally meaningless yet functionally meaningful. And we argue that it is viewpoint that makes the formally meaningless functionally meaningful.

Lyons (1977: p. 33) discussed both meaningfulness and choice in term of information transmission. Meaningfulness includes two senses or aspects: 1) a signal is communicative if the information sender intends to make the receiver aware of something of which he was not previously aware, which rests upon the possibility of choice, or selection, on the part of the sender. It depends on one of the most fundamental principles of seman- 
tics-the principle that choice, or the possibility of selection between alternatives, is a necessary, though not sufficient, condition of meaningfulness. This principle is frequently expressed in terms of the slogan: meaning, or meaningfulness, implies choice; 2) a signal is informative if (regardless of the intentions of the sender) it makes the receiver aware of something of which he was not previously aware. "Informative" therefore means "meaningful to the receiver". If the signal tells him something he knew already, it is uninformative (thus meaningless). The previously mentioned slogan (meaningfulness implies choice) can thus be interpreted from either the sender's or the receiver's viewpoint. It is worth observing that sender's meaning involves the notion of intention and receiver's meaning the notion of value, or significance. In other words, meaninglessness means what is informed by the information sender has nothing new and interesting to the receiver.

Since meanings are subjective they are also viewpoint-oriented by nature. Whenever we intend to express our personal ideas or our understanding of others' utterances, we often use such viewpoint adjunct like "from my point of view", "as far as I'm concerned", or "from my perspective". However, viewpoint can be expressed together with meaning in more other ways than viewpoint adjunct. Noun phrases with ideological and attitudinal sense like "hero" or "traitor", verb phrases like "hate" or "love", adjective phrases like "fat" or "plump" can all be used to show meaning with viewpoint.

The contents of word meaning, and the context-situated enriched meanings of words, are highly subjective in that they reflect especially human concerns and their viewpoints. Enfield (2015: pp. 4-5) argues that word meaning embody a human viewpoint in more than one sense: one is that humans have a special propensity for attributing psychological motives behind actions and behavior. Even in non-human referential domain of landscape features, a deeply anthropocentric perspective is still encoded, especially on account of the intrinsically subjective nature of affordance. The third is that cultural expectations can guide the interpretation and selection of words in grammatical contexts, showing us how cultural perspectives are manifest both on the syntagmatic axis and the paradigmatic axis.

Halliday (1992: p. 22) thinks that meanings are also intersubjective since there can be no meaning without expression. What he means can be put in more detail: expression occurs only when participants of both parties in communication intend to make and interpret meaning by producing expressions, or a certain linguistic structure, or form, or wording, and result from choosing among all possible realizational devices for a certain meaning, or function, which inevitably brings their own viewpoints as essential element into communicative context. In other words, a linguistic form may mean either anything or nothing with a definite context of situation in communication.

Viewpoint, as an essential component of our cognition, has great influence on our meaning making and interpreting. Langacker (2008) specifically invokes the role of cognition, arguing that cognition has a significant role in determining the meaning of an expression. Dancygier and Sweetser (2012) argue that human cognition is not only rooted in the human body, but also inherently viewpointed as a result, and language 
and communication are the case. For example, we have the conceptual capacity for construing events as abstract objects.

Without the personal and subjective involvement of the language users, or participants in communication, meaning creating or conveyance and meaning understanding or acceptance will become almost impossible. Narayan (2012: p. 115) holds that meaning construction is a collaborative and interactive process of both speaker and hearer, and this process may fail due to a viewpoint shifting or misunderstanding. Ferrari and Sweetser (2012: p. 47) propose an analysis of historical processes of meaning subjectification, in terms of viewpoint relation in a dynamic network of mental spaces and argue that defining subjectification in terms viewpoint relations allows added precision both in identifying subjective aspects of meaning and assessing degrees of subjectivity and hence in accurately describing directions of meaning change.

Taking viewpoint into consideration, the above exemplary sentences (1)-(3) in the introduction can all be found meaningful and mean a lot. (1) uttered by a child often means his or her pride of having a manly, strong and perhaps wise father who can offer paternal love, protection, or timely assistance. (2) mostly refers to the cruelty of war. From the viewpoint of the direct war participants-the soldiers, war means injury, blood, and death; or from the viewpoint of the soldier's parents, wife and children, war means the possibility of forever losing their son, husband and father; and from the viewpoint of hundreds and thousands of common people, war means suffering, tears, and losing the home, property, and even life. But from the viewpoint of weapon manufacturers and warlords, war may mean making a fortune by selling weapons or seizing wealth by robbing and killing. In the same way, from the viewpoint of parents or teachers, (3) generally means boys are naughtier than girl; from the viewpoint of girls of the same age, it may mean boys are physically stronger hence are able to carry heavier stuffs.

Still a further typical example is US former secretary of defense Rumsfeld's most famous statement as an answer to a correspondent's question of "What evidence do you have that Iraq is supplying terrorists with W.M.D. (weapon of mass destruction)?"

(11) As we know, there are known knowns; there are things we know we know. We also know there are known unknowns; that is to say we know there are some things we do not know. But there are also unknown unknowns-the ones we don't know we don't know.

This statement was commonly viewed as obviously meaningless, or nonsense and laughingstock since it is not at all an answer to the question nor does it tell anything new and interesting to the correspondents. But some people think it smart and brilliant from a viewpoint of political and diplomatic tact.

\section{Conclusion}

As is discussed in the above sections, meanings are first of all multilayered; then they are optional and subjective; eventually, meanings expressed are a result of choosing from a set of possibilities or meaning potentials. These features of meaning share an in- 
terrelationship of cause and effect in that multilayeredness leads to optionality, which involves subjective choice of meaning from the language users' viewpoint. Meaning, especially meaning creation as well, is, in a great degree, subjective and thus viewpointoriented. Just as the saying goes "One man's meat is another man's poison," some linguistic forms or structures are meaningful from one man's viewpoint and meaningless from another man's viewpoint. Some seemingly meaningless language forms are meaningful in an authentic communicative context. Meanings can be lexicogrammatically and linguistically varied and shaped, and therefore, formally viewpointed. It can also be emotionally or attitudinally influenced and determined, and hence functionally viewpointed. Successful meaning conveyance and interpretation is primarily to people's communication end and again is viewpoint-oriented by nature.

To conclude, meaning is right there as soon as any linguistic form is produced. However, whether this linguistic form being meaningful or meaningless, or its meaning being multilayered or single-layered, depends all on the language user's viewpoint. If her viewpoint is from a formal, literal or conventional one, some linguistic form must be meaningless. If her viewpoint is from a functional, emotional, unconventional, or pragmatic one, meanwhile taking ideology, stance, or context into consideration, these formally meaningless linguistic forms will become informative and meaningful. It is viewpoint that helps make a seemingly meaningless or even nonsense text meaningful.

\section{References}

Caffarel, A. (2006). Learning Advanced French through SFL. In H. Byrnes (Ed.), Advanced Language Learning: The Contribution of Halliday and Vygotsky (pp.204-24). London: Continuum.

Caffarel, A. (2010). Systemic Functional Grammar and the Study of Meaning. In B. Heine, \& H. Narrog (Eds.), The Oxford Handbook of Linguistic Analysis (pp. 797-825). Oxford: Oxford University Press.

Dancygier, B., \& Sweetser, E. (2012). Viewpoint in Language: A Multimodal Perspective. Cambridge: Cambridge University Press. https:/doi.org/10.1017/CBO9781139084727

Eggins, S. (2004). An Introduction to Systemic Functional Linguistics (2nd ed.). London: Continuum.

Enfield, N. J. (2015). The Utility of Meaning. Oxford: Oxford University Press.

Ferrari, L., \& Sweetser, E. (2012). Subjectivity and Upwards Projection in Mental Space Structure. In B. Dancygier, \& E. Sweetser (Eds.), Viewpoint in Language: A Multimodal Perspective (pp. 47-68). Cambridge: Cambridge University Press.

https:/doi.org/10.1017/CBO9781139084727.005

Halliday, M. A. K. (1978). Language as Social Semiotic. London: Edward Arnold.

Halliday, M. A. K. (1992). How Do You Mean? In M. Davies, \& L. Ravelli (Eds.), Advances in Systemic Linguistics: Recent Theory and Practice (pp. 20-35). London: Pinter Publishers.

Halliday, M. A. K. (1994). An Introduction to Functional Grammar. London: Edward Arnold.

Halliday, M. A. K., \& Matthiessen, C. M. I. M. (2004). An Introduction to Functional Grammar (3rd ed.). London: Arnold.

Langacker, R. W. (2008). Cognitive Grammar: A Basic Introduction. Oxford: Oxford University Press. https:/doi.org/10.1093/acprof:oso/9780195331967.001.0001

Löbner, S. (2002). Understanding Semantics. London: Hodder Arnold. 
Löbner, S. (2013). Understanding Semantics (2 ${ }^{\text {nd }}$ ed.). London: Routledge.

Lyons, J. (1977). Semantics (Vol. 1). Cambridge: Cambridge University Press.

Narayan, S. (2012). Maybe What It Means Is He Actually Got the Spot: Physical and Cognitive Viewpoint in a Gesture Study. In B. Dancygier, \& E. Sweetser (Eds.), Viewpoint in Language: A Multimodal Perspective (pp. 113-135). Cambridge: Cambridge University Press. https:/doi.org/10.1017/CBO9781139084727.009

Riemer, N. (2005). The Semantics of Polysemy: Reading Meaning in English and Warlpiri. Berlin: Mouton de Gruyter.

Submit or recommend next manuscript to SCIRP and we will provide best service for you:

Accepting pre-submission inquiries through Email, Facebook, LinkedIn, Twitter, etc. A wide selection of journals (inclusive of 9 subjects, more than 200 journals)

Providing 24-hour high-quality service

User-friendly online submission system

Fair and swift peer-review system

Efficient typesetting and proofreading procedure

Display of the result of downloads and visits, as well as the number of cited articles

Maximum dissemination of your research work

Submit your manuscript at: http://papersubmission.scirp.org/

Or contact ojml@scirp.org 